\title{
MODELLING SHORELINE EVOLUTION IN RESPONSE TO CLIMATE CHANGE
}

\begin{abstract}
Anna Zacharioudaki ${ }^{1}$ and Dominic E. Reeve ${ }^{2}$
In this paper we examine the evidence for detectable climate change impacts on shoreline evolution. In a sequentially linked set of models, climate change scenarios are taken from atmospheric climate models and used to generate time slices of deepwater wave climate, nearshore wave climate and shoreline evolution. The models used are simple, containing the key physical processes only. Results are based on a hypothetical case which has some similarities to a site on the south coast of the UK. Output from the model is analysed using a robust statistical methodology to determine the evidence for statistically significant differences between beach behaviour under current conditions and several future scenarios. Statistically significant differences vary with season and also with the combination of climate model outputs used for input. Summers are the only season for which all models showed significant changes, corresponding to an increase in the net eastward littoral transport.
\end{abstract}

Keywords: modeling, shoreline, climate change, statistical significance

\section{INTRODUCTION}

\section{Background}

IPCC predictions of sea level rise are well-known (IPCC WG1, 2007). These are based on different emissions scenarios corresponding to a variety of politico-economic situations (IPCC SRES, 2000). The emissions scenarios have also been used to create future global weather scenarios in order to investigate potential changes in our climate and weather. Figure 1 shows the various sea level predictions, taken from the IPCC website.

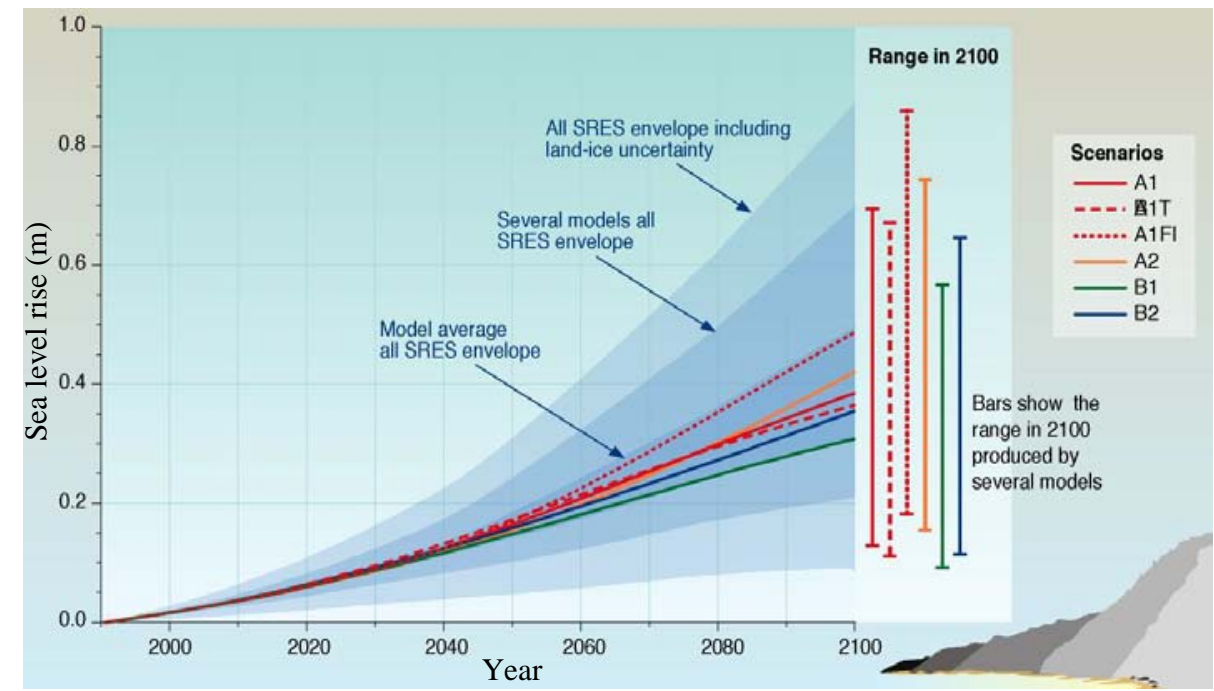

Figure 1. Global average sea level rise for the different IPCC emissions scenarios.

The imminent effects of climate change have been discussed at length in the news media. A large body of work on this subject also exists in the scientific and engineering literature. At this time there is no consensus on the veracity of the IPCC predictions as forecasts, as opposed to possible scenarios. Indeed, although the seeming majority of the scientific research seems to support the contention that emissions will lead to changes in our climate, there remains a sizeable minority with the contrarian viewpoint. That relative sea levels have been changing significantly over a decadal scale can be seen in the tide gauge records of many ports, (most going up and some going down due to isostatic rebound). Changes in temperatures, rainfall and wind patterns are more difficult to identify explicitly due both to the large inherent natural variability in these quantities and also the fact that many such measures are compiled from groups of recorders and thus represent a spatial and/or temporal average.

\footnotetext{
${ }^{1}$ Centre of Marine and Environmental Research CIMA, University of the Algarve, Campus of Penha, Faro, Algarve, 8005-139, Portugal

${ }^{2}$ Coastal Engineering Research Group, School of Marine Science and Engineering, University of Plymouth, Drake

Circus, Plymouth, Devon, PL4 8AA, United Kingdom
} 
The debate over the existence and impacts of climate change has been fanned recently by the 'climategate' incident. This involved the hacking of emails at the Climate Research Unit at the University of East Anglia in the UK and subsequent commentary on, and investigation into, the methods employed by researchers in their climate change research. An (evolving) summary of the incident can be found on Wikipedia (2010). The incident has attracted wide media and police attention. Indeed, Christopher Booker of the UK Daily Telegraph has written, 'Climate change: this is the worst scientific scandal of our generation - Our hopelessly compromised scientific establishment cannot be allowed to get away with the Climategate whitewash'. Leading academics at the Climate Research Centre have been interviewed by the local police and scientists across the world, involved in climate change research, have received threatening emails.

\section{Motivation}

In this fast-moving and opaque situation it is difficult to assess what can be trusted and what should be discarded. What is clear from a consideration of the physical processes is:

- There is the potential for changes in both relative sea level rise and 'storminess'. That is, alterations in the nature of the storm tracks, storm intensity and storm duration. Irrespective of the veracity of the claims of either side in the climate change debate it is simply prudent to explore the possible changes so that we can plan for appropriate responses in the event that climate change does occur in the way suggested by IPCC;

- that the variability in natural systems, be it rainfall or beach levels, can be large. This means detecting change is fraught with problems and is best assessed by analysing changes in the statistical properties of the variable(s) of interest. In turn this requires long term measurements or scenario predictions in order to construct robust statistical measures.

In this context we find ourselves with several different future climate change scenarios. We can use these to create time series of variables from which statistics can be constructed. We have no means of testing whether the future scenarios are 'true' but the theory of statistics does provide us with tools to test where the different scenarios are significantly different in a statistical sense.

In this paper we use output from meteorological climate models, usually termed general circulation models or GCMs, to drive a simplified case of shoreline change. The results for different scenarios are compared using robust statistical methods in order to determine whether there are any significant differences to the shoreline response between scenarios.

\section{METHODOLOGY}

The structure of the study is summarised in Figure 2:

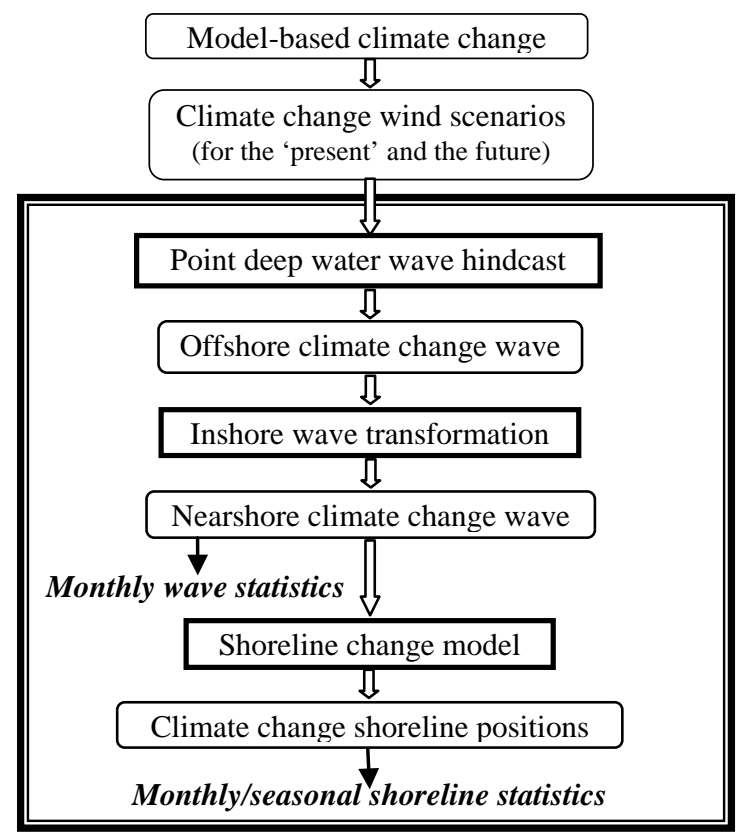

Figure 2. Data flow and structure of the elements of the analysis. 


\section{Surface Winds}

Winds were sourced from the PRUDENCE project, (Christensen et al 2007). Wind output from a number of time-slice (30-year) experiments (Table 1), done within the framework of the PRUDENCE project was used in this study. Data come from one regional climate model, (RCM), called HIRHAM (Christensen et al., 1996) at two spatial resolutions, $12 \mathrm{~km}$ and $50 \mathrm{~km}$ respectively. Wind output frequency is 3 hours. Only the medium-high A2 SRES scenario was available at $12 \mathrm{~km}$ resolution. Both A2 and the medium-low B2 scenarios were available at $50 \mathrm{~km}$ resolution. At $50 \mathrm{~km}$ resolution, output from HIRHAM driven by two GCMs was obtained. One is the HadAM3H (Pope et al., 2000) which is a high resolution $\approx(120 \mathrm{~km}) \mathrm{GCM}$ of the atmosphere only. The other is the ECHAM4/OPYC (Roeckner et al., 1996) which is a coarser resolution $₹ 300 \mathrm{~km}$ ) combined ocean-atmosphere GCM. Simulations driven by the former GCM are referred to as HIRHAM-H (-H12 if at 12km resolution and -H50 if at $50 \mathrm{~km}$ ) in the following whilst those driven by the latter GCM will be referred as HIRHAM$\mathrm{E}$ (-E50). These two experiments also differ with respect to the monthly mean SSTs used to drive the climate models and the nature of the wind output. In the first experiment (HIRHAM-H) the SSTs used in the 'control' experiment are monthly mean observations whilst instantaneous winds are output. In the second experiment (HIRHAM-E) SSTs are taken directly from the driving AOGCM whilst 3hourly average winds are output. The use of observed SSTs better constrains a GCM towards the observed climate (Christensen and Christensen, 2007). A pictorial summary of the different models is shown in Figure 3.

Table 1. Climate model time-slice experiments used in this study

\begin{tabular}{|c|c|c|c|c|c|c|c|}
\hline \multirow[t]{2}{*}{ RCM } & \multirow[t]{2}{*}{ AGCM } & \multirow{2}{*}{$\begin{array}{l}\text { RCM } \\
\text { Resolution }\end{array}$} & \multirow[t]{2}{*}{ SRES } & \multirow{2}{*}{$\begin{array}{l}\text { Control } \\
\text { period }\end{array}$} & \multirow{2}{*}{$\begin{array}{l}\text { Scenario } \\
\text { period }\end{array}$} & \multicolumn{2}{|c|}{ Abbreviations } \\
\hline & & & & & & control & scenario \\
\hline HIRHAM & HadAM3H & $12 \mathrm{~km}$ & $\mathrm{~A} 2$ & $1961-1990$ & $2071-2100$ & C12 & A12 \\
\hline HIRHAM & HadAM3H & \multirow[b]{2}{*}{$50 \mathrm{~km}$} & A2 & $1961-1990$ & $2071-2100$ & \multirow{2}{*}{ HC50 } & HA50 \\
\hline HIRHAM & HadAM3H & & B2 & $1961-1990$ & $2071-2100$ & & HB50 \\
\hline HIRHAM & ECHAM4 & \multirow{2}{*}{$50 \mathrm{~km}$} & A2 & $1961-1990$ & $2071-2100$ & \multirow{2}{*}{ EC50 } & EA50 \\
\hline HIRHAM & ECHAM4 & & $\mathrm{B} 2$ & $1961-1990$ & $2071-2100$ & & EB50 \\
\hline
\end{tabular}

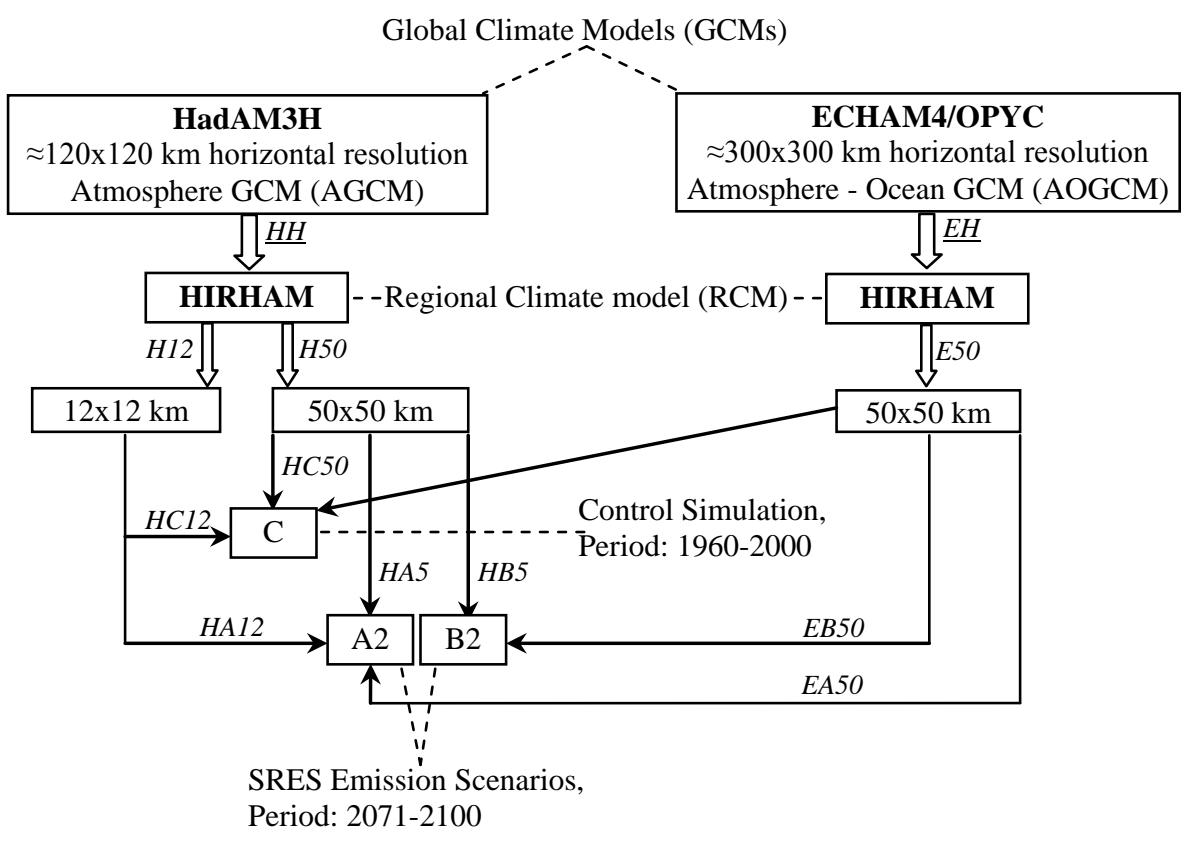

Figure 3. Relationships between the different GCMs, RCMs and climate scenarios.

Wind data consisted of the zonal and meridional components of the wind vector at two offshore locations corresponding to the two horizontal RCM resolutions. Thus, the data location for the $12 \mathrm{~km}$ resolution climate experiment is at $50.5246^{\circ}$ North and $-1.6410^{\circ}$ East whilst for the $50 \mathrm{~km}$ resolution experiments is at $50.5965^{\circ}$ North and $-1.5942^{\circ}$ East. Location coordinates correspond to the middle of 
the grid cells (e.g. $12 \mathrm{~km} \times 12 \mathrm{~km}$ grid cell for the $12 \mathrm{~km}$ resolution experiment) and are situated at the south central coast of England, offshore Poole Bay. Figure 4 depicts these locations (solid squares) along with the extent of the corresponding grid cells, the box inside the figure for the $12 \mathrm{~km}$ resolution and the whole figure extent for the $50 \mathrm{~km}$ resolution. Both cells embrace a UK Met Office wave hindcast point (offshore dot) which is located at $50.50^{\circ}$ North and $-1.66^{\circ}$ East, at $33 \mathrm{~m}$ water depth. Nearshore, the dot denotes a refraction point, located at Hengistbury Head, at $50.7097^{\circ}$ North and $1.7493^{\circ}$ East, and at 3.5m water depth (ODN). All the 30-year time-series of 3-hourly winds corresponding to the different simulations of Table 1 were used in the analysis.

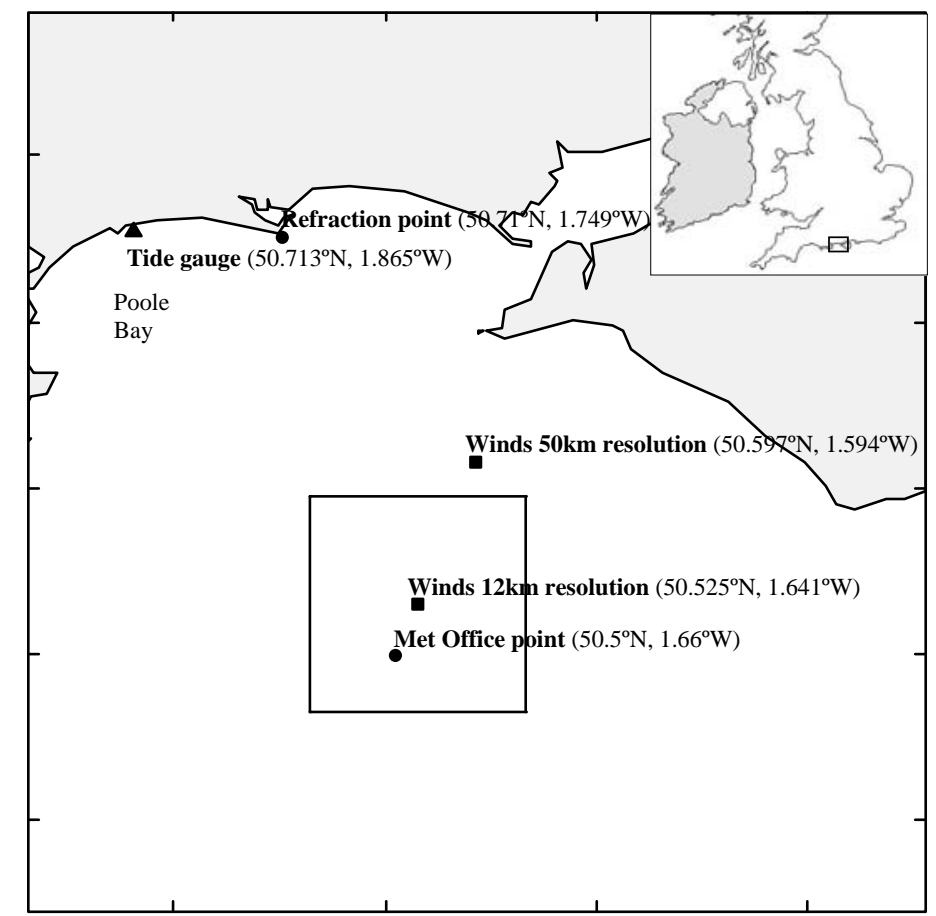

Figure 4. Wave data locations offshore Poole Bay including 1) locations of RCM wind data (solid squares), 2) the Met office hindcast data location (offshore dot), 3) a nearshore refraction point (inshore dot), and 4) a tide gauge (inshore triangle).

\section{Wave hindcasting and transformation}

This starts with the hindcast of deep water wind waves and continues with their inshore transformation. Thus, 30-year time-series of 3-hourly nearshore wind waves are generated for each of the different experiments of Table 1. A parametric, point hindcast model, based on modified SMB hindcast expressions which account for non-coincident wind and wave directions for fetch limited waves, was used to hindcast deep water waves for the full set of wind data. Its basic formulae are documented in Donelan (1980) and CERC (1977). Required model input is also the fetch lengths extending from the hindcast location to the surrounding coastline in radials at specified direction intervals. Here, fetch lengths were calculated for the Met Office point (Figure 4), on the assumption that spatially averaged winds corresponding to the climate model output locations would be approximately the same as at the Met Office point.

Inshore wave characteristics, $\left(H_{s}, T_{p}\right.$, and direction), were determined from the offshore hindcast wave data using a ray back-tracking spectral energy transformation model, (eg. Abernethy \& Gilbert 1975), which accounted for tidal water variations and spectral saturation. Nearshore tidal levels, required over the wave transformation periods, were predicted from known tidal constituents (62 constituents) at the Bournemouth tide gauge (Figure 4), located at 50.7127 North and -1.8653025 East. Transformation took place from the Met Office point in deep water to the Refraction point at approximately 3.5m water depth. Each 30-year near shore wave time series took approximately 15 minutes to generate from the deep water conditions on a desktop PC. 
The wave hindcast model was calibrated using a 17-year (1988-2005) hindcast wave time-series (3-hourly) at the Refraction point. This time-series was generated by transforming inshore deep water hindcast waves obtained at the Met Office point, using the 25km resolution Met Office European Waters wave model. This has previously been extensively validated and has shown reasonable agreement with measurements (Bradbury et al., 2004). Overall, the calibrated SMB-Donelan model, produced waves with characteristics reasonably close to the 'actual'. Therefore, even if lacking some of the swell component that is sometimes detected in deepwater wave buoys, it is a highly realistic wave time-series for investigating the influence of the relative changes between wave climate scenarios on the changes of a hypothetical shoreline stretch.

\section{Beach model}

Here, we used a 'one-line' model to investigate changes in the evolution of a hypothetical stretch of shoreline under the various nearshore wave climate scenarios. The numerical 'one-line' model of Zacharioudaki \& Reeve (2010), using the method of lines solution techniques, was used. The equation solved by the numerical model is the continuity of sediment equation as given by Cowell et al. (2003) with all local source terms $(q)$ set to zero. The sediment transport formula is the well-known CERC formula. A depth of closure, $D_{c}$, of $10 \mathrm{~m}$ was assumed. Parameters in the CERC formula were set as: $K$ $=0.41$, water depth $=3.5 \mathrm{~m}$ which is the reference depth of the input waves, $\rho_{s}=2650 \mathrm{~kg} / \mathrm{m}^{3}$ (quartzdensity sand), $\rho=1020 \mathrm{~kg} / \mathrm{m}^{3}$ (sea-water density), and $\sigma=0.6$ (Komar, 1998). Diffraction is neglected and wave characteristics are assumed constant alongshore. The case of shoreline evolution examined is that of an initially straight shoreline that is bounded on the right hand side by a long impermeable groyne. The shoreline is fixed at the left hand boundary. The shoreline extent was taken to be $15000 \mathrm{~m}$ which was sufficient to ensure that the assumption of a pinned beach at the LHB has no affect on the results. The initial beach plan shape is given by $y(x, 0)=0$ and the shoreline normal was taken to be $178^{0}$ from North. In the time slice simulations the beach is 'reinitialised' to its initial configuration at the end of each season. Thus the output would be 30 sets of beach positions over each season, each with the initial condition of a straight beach. This procedure is somewhat artificial but does remove issues about long range temporal correlation effects. The output from the 30 realisations of each season can be used to compute various statistics, as shown in the results section.

The situation described is hypothetical. Nevertheless, it retains some of the features of the shoreline fronting Hengistbury Head (area shoreward of the Refraction point of Figure 4). Specifically, the stretch of shoreline extending from the eastern tip of Poole Bay to about $1500 \mathrm{~m}$ to the west is relatively straight and bounded on the right hand side by a long groyne, SCOPAC (2003).

\section{Statistical testing}

If we consider two samples of the same quantity, for example seasonal mean wave heights for the control run and a scenario, they can be tested in suitable pairs for significant differences. The twosample $t$-test can show if two independent samples having a normal distribution with unknown equal (or, optionally, unequal) variances, have the same mean or not. The test accepts or rejects the 'nullhypothesis' that the two input samples, $x, y$, have equal means at a user specified significance level, alpha. The latter can be interpreted as the probability of rejecting the 'null-hypothesis' when it is actually true. For example, for a common value of alpha $=0.05$ there is a $5 \%$ probability that the test result is false. Rejection or acceptance of the 'null-hypothesis' depends on the $p$ value, which is the probability of obtaining by chance a value of the test statistic as extreme or more extreme than the value computed from the sample. If $p>$ alpha the test accepts the 'null-hypothesis'. If $p<$ alpha the test rejects the 'null hypothesis'. The confidence interval, $c i$, denotes the range of mean values with a 100 (1-alpha)\% probability of containing the true mean of the difference.

The $t$-test assumes that the data follow a normal distribution, that no serial autocorrelation exists (i.e. subsequent values in the sample are independent), and that the sample is statistically stationary. The first assumption may be ignored for relatively large samples. The third assumption, although the 30-year future simulations are not stationary because of the gradually increasing greenhouse gas forcing, is also overlooked following the arguments of Räisänen et al. (2003) who suggested that this effect is expected to be small. However, serial autocorrelation may severely impact on the test performance by causing the test to find significant differences when there are not (Zwiers and von Storch, 1995). The climate data do exhibit some autocorrelation. Its brief characteristics and a means of dealing with it are described in Zacharioudaki (2008).

Another test we use is the Kolmogorov-Smirnov, $(\mathrm{ks})$, test. This is a conventional non-parametric test which compares the distribution of two samples. Test inputs and outputs are as for the $t$-test except for the $c i$ term which is not applicable in this case. Now, the 'null hypothesis' is that the two samples 
come from the same distribution. Like the $t$-test, the $k s$-test performs better when no serial autocorrelation exists. The mathematics of both the $t$-test and $k s$-test can be found in established statistical textbooks (e.g. Freud, 1992).

\section{RESULTS}

\section{Wave conditions}

Figure 5 shows summary comparisons of wave conditions at the Refraction point of Figure 4 for cases HC50, HA50 and HB50.
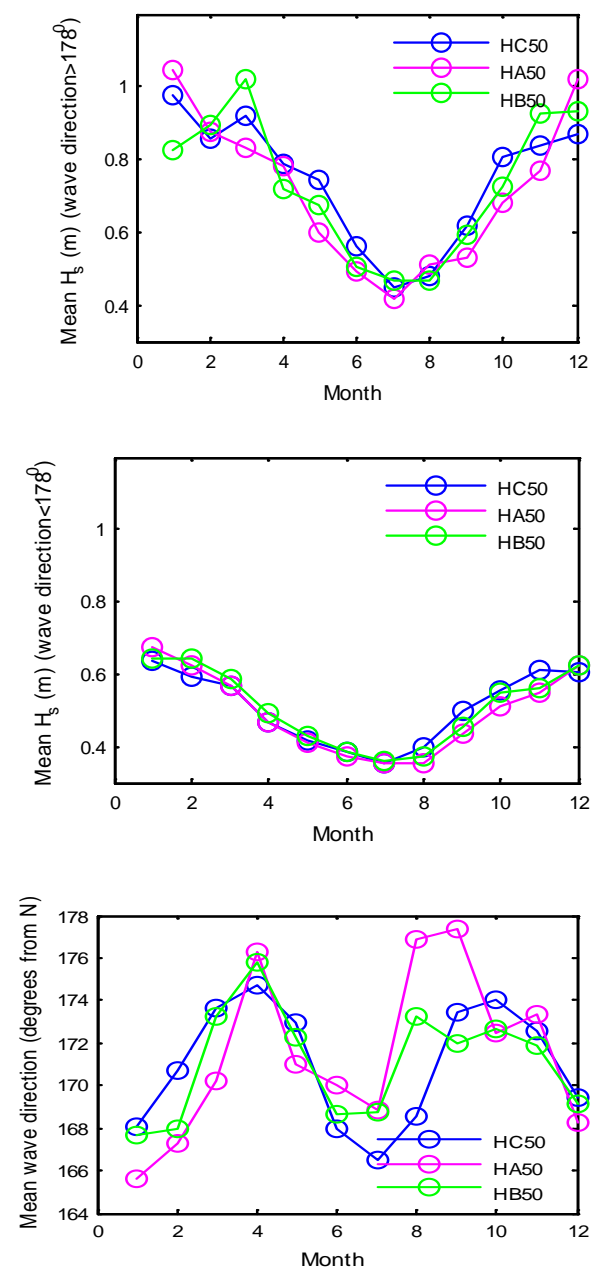

Figure 5. Monthly averages of nearshore wave heights and directions: (top) wave heights from southwest quadrant; (middle) wave heights for waves from southeast quadrant; (bottom) wave direction. Blue, pink and green lines correspond to control, A2 and B2 scenarios respectively (see Table 1).

There is very little obvious change to wave heights of waves from the southeast quadrant. There are however larger changes in wave height in waves from the southwest quadrant, particularly in the winter months. Changes in monthly mean wave direction of up to $10^{\circ}$ are evident. This figure is typical of the many comparisons performed. Overall, the results can be summarised as:

- $\quad$ Prevailing winter waves are generally higher in the future than in the 'present';

- $\quad$ Prevailing autumn waves, including August, are lower in the future;

- $\quad$ Summer and spring waves are largely unchanged in terms of $H_{s}$;

- There is general agreement in the trends of changes in wave conditions with earlier studies (Kaas et al., 2001; Sutherland and Gouldby, 2003; Hulme et al., 2002; Beniston et al., 2007);

- Significant differences are more generally found between different climate models than between different scenarios. 


\section{Shoreline scenarios}

The results of the beach modeling and statistical testing are presented in a compact style which is best explained with the following example shown in Figure 6. The $\mathrm{x}$-axis represents the long shore dimension and shows the rightmost $900 \mathrm{~m}$ of the domain. The vertical axis is the distance of the shoreline contour from its starting position of $0 \mathrm{~m}$. The full lines show the ensemble average position of the shoreline at the end of the season. For comparison the median positions at the end of the season are also shown. If the realizations have a skewed distribution then this will be reflected by differences between the mean and median. Also shown is a measure of the variation in the sample, here lines corresponding to \pm 3 standard deviations are drawn.

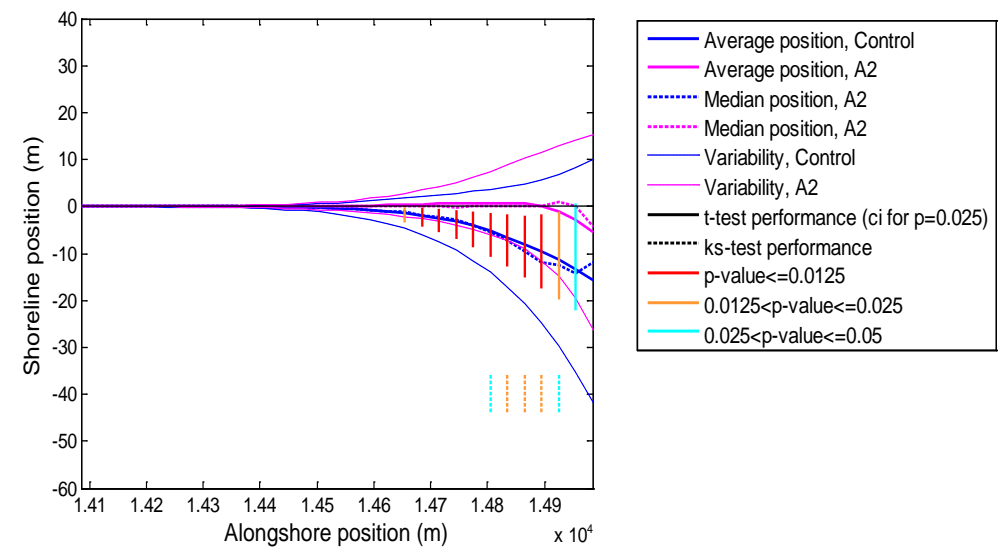

Figure 6. Example showing the style and content of beach modeling shown subsequently. This figure shows, for a particular season, the mean (full line) and median (dashed line) shoreline positions for both the control case (blue) and scenario (magenta). The 'variability' $( \pm 3 \sigma)$ of the shoreline position over the season for both cases is shown in light dashed lines of the appropriate colour. Results of the statistical tests are shown as vertical bars. More details on these may be found in the text.

Results of the comparative statistical tests are shown by the vertical lines drawn at discrete longshore positions. Only lines that correspond to a statistically significant change $(p \leq 0.05)$ in mean shoreline position between present and future are drawn. The $t$-test results are plotted as variable length coloured bars. The position and length of the bars are associated to the confidence interval computed using a significance level of $5 \%$. The colour corresponds to the $p$-value obtained from the test. The range of shoreline position values associated with each of the bars represents all possible values the difference in the mean of the two samples can attain at the specific longshore location under a $95 \%$ confidence level, i.e. leaving a 5\% probability of getting a value outside this range. Clearly, the longer the bars are the greater the aforementioned range. Also, the more coloured towards the red end of the spectrum the bars are the smaller the value of $p$, signifying that the probability that we have rejected the null hypothesis when in fact it is true decreases similarly. Obviously, the smaller the $p$ value is the greater certainty in the result. The $k s$-test results are plotted as coloured bars of constant length. Colour conventions are as for the $t$-test.

\section{Results for A2}

Comparisons between the control run and the A2 scenario are shown in Figures 7 and 8 for the HIRHAM-H12 and HIRHAM-E50 experiments respectively. Figure 7 shows significant future changes in shoreline positions in all seasons except for autumn. Specifically, in winter and spring, significant future erosion is predicted whilst in summer the shoreline is predicted to significantly accrete. The maximum future displacement in mean shoreline position is in winter and it is $26 \mathrm{~m}$. In spring, the estimated change is in the distribution of seasonal shoreline positions rather than in the mean position. An example of a distributional change is presented in Figure 9. This figure shows non-parametric distributions of yearly shoreline positions at a location where the $k s$-test rejected the 'null-hypothesis' with a high certainty. Although no significant difference in the mean values of the shoreline position was found between control and scenario, the distributions reveal that future shoreline positions are onshore with higher probability densities, mostly falling within a narrower band of values $₹-100-5 \mathrm{~m}$ ), and exhibit almost zero probability of being $>50 \mathrm{~m}$. The results obtained for the coarser resolution HIRHAM-H50 (not shown) differed occasionally in the distribution of significant changes. In particular, in winter, this experiment produced no significant changes whilst in spring and summer, 
somewhat higher certainty of change was predicted and over a greater number of alongshore locations. Figure 8 shows that summer is the only season for which statistically significant future changes are predicted for the HIRHAM-E50 A2 scenario. A very high certainty is pertained to these changes ( $p<<$ 0.0125). In accordance with the HIRHAM-H experiments, future erosion is predicted in winter and spring and accretion in summer for this scenario. In contrast to the HIRHAM-H experiments, future erosion is predicted also in autumn. Nevertheless, the differences between control and scenario mean shoreline positions for this season are very small for both experiments. The maximum mean shoreline shift is found to be in summer and is $30 \mathrm{~m}$.
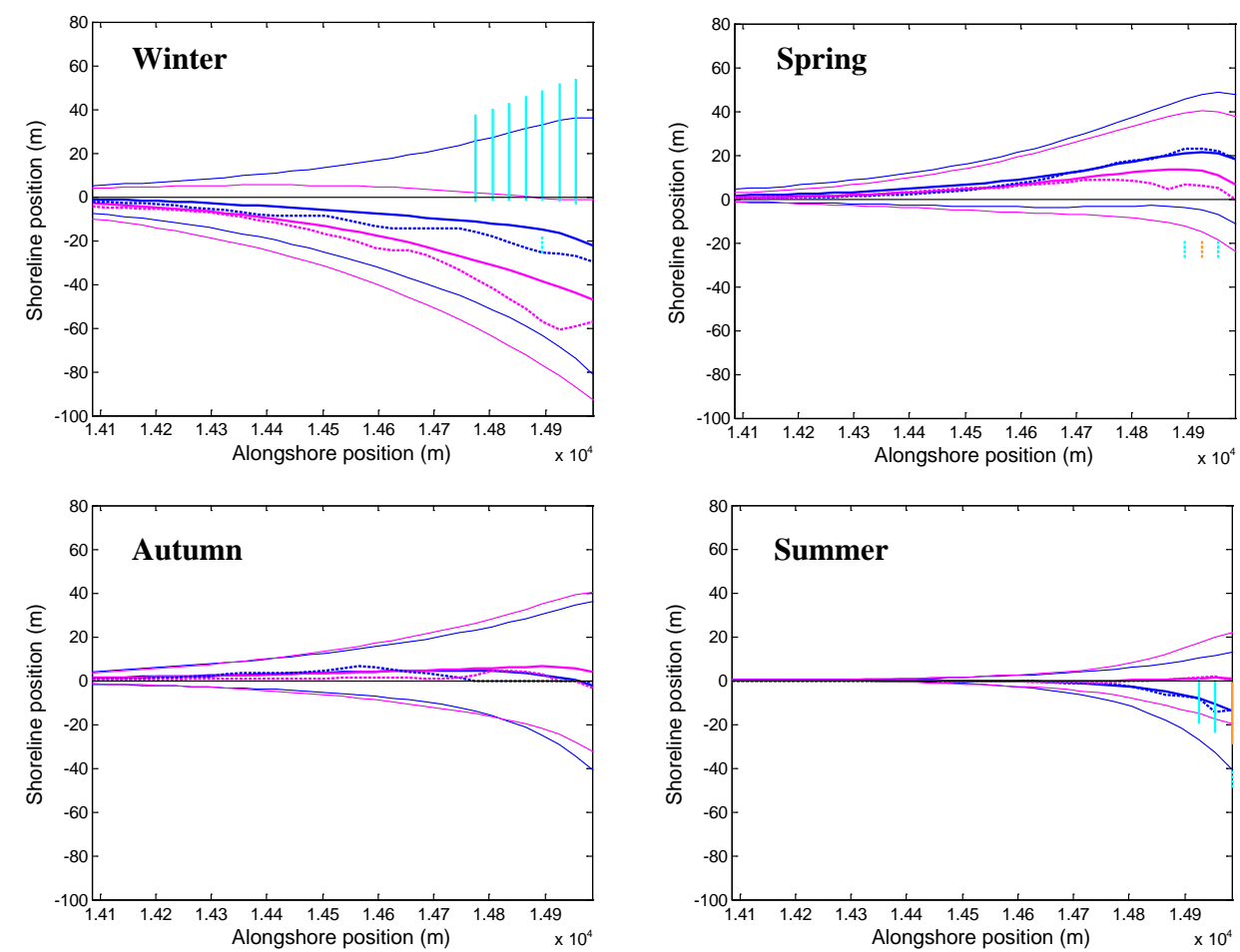

Figure 7. Results for the four seasons for the HIRHAM-H A2 scenario at $12 \mathrm{~km}$ resolution. Formatting scheme is as shown in Figure 6. 

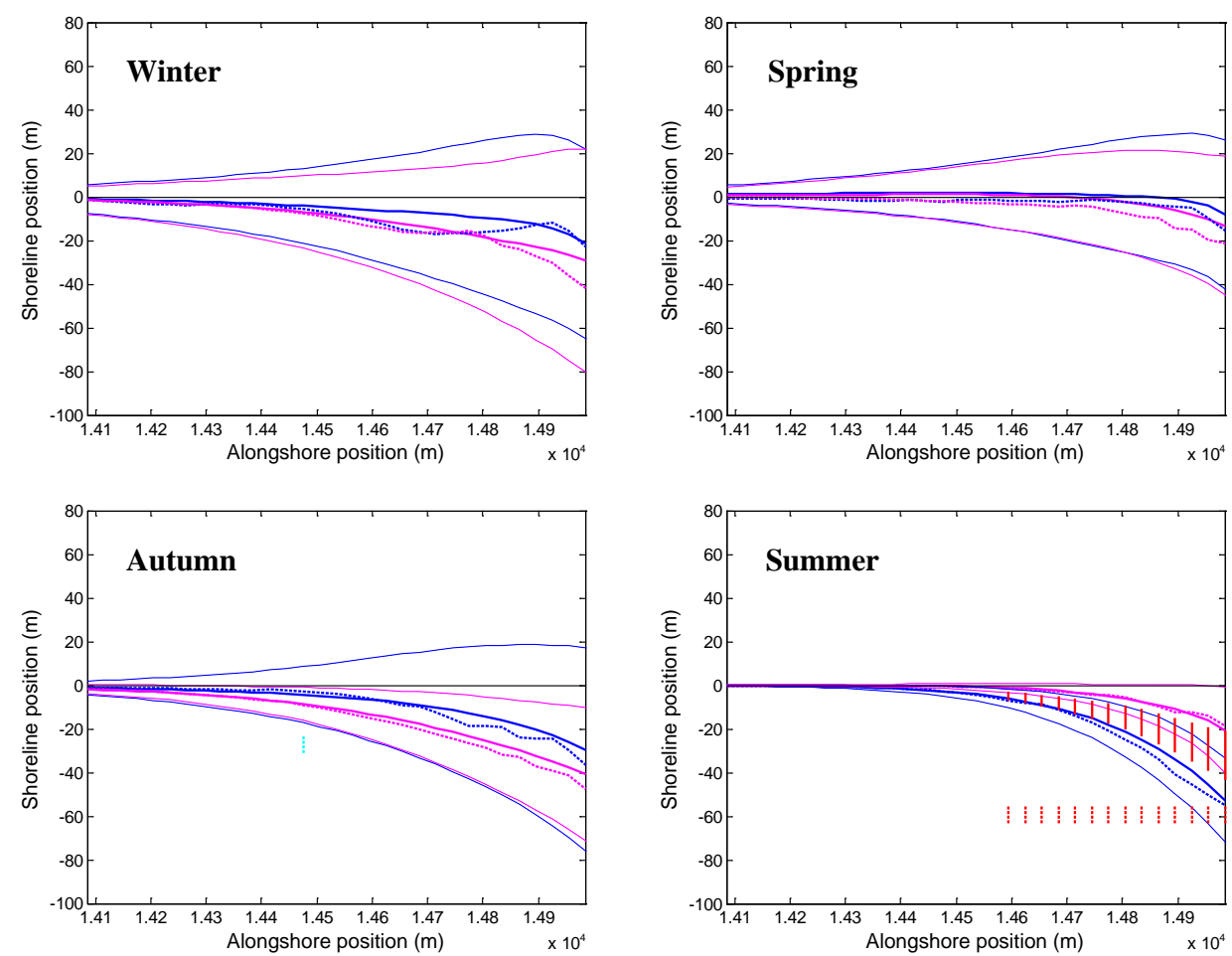

Figure 8. Results for the four seasons for the HIRHAM-E A2 scenario at $50 \mathrm{~km}$ resolution. Formatting scheme is as shown in Figure 6.

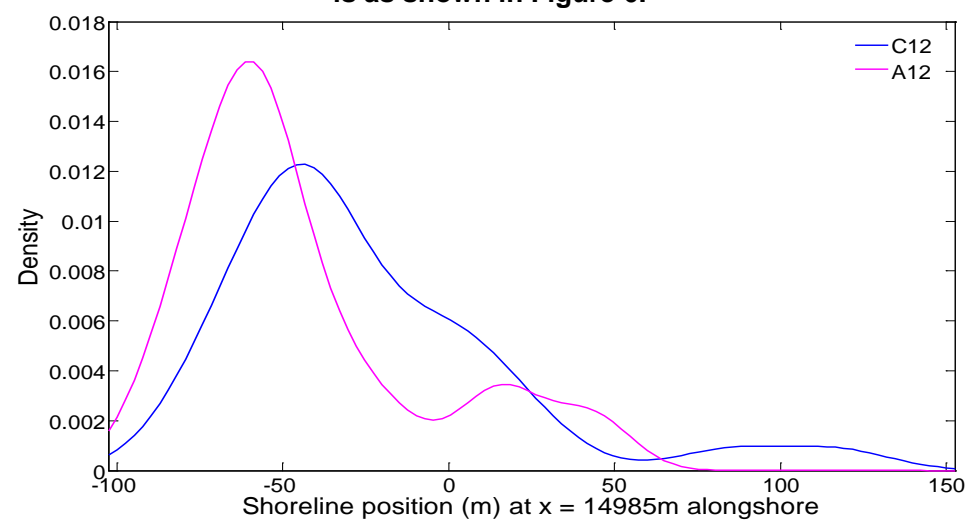

Figure 9 Yearly shoreline positions distribution for $\mathrm{C} 12$ and $\mathrm{A} 12$ at a specific alongshore location.

The estimated differences between control and scenario were found to be closely linked to differences in the input wave characteristics. For example, focusing on the HIRHAM-H experiments, a significant eastward veering of the mean wave direction was found in the future during winter (see Figure 5 - similar results for the HIRHAM-H12 experiment). This alone implied the possibility for greater future erosion west of the long-groyne. However, combined with a significant increase in the mean $H_{s}$ of southeasterly waves enhanced our expectation for significantly increased future erosion during winter, as indeed observed in Figure 7. Similarly, in summer, significant future shoreline accretion relative to the control may be explained by a significant westward veering of the mean wave direction along with a decrease of $H_{s}$ of waves approaching the coastline from west sectors (Figure 5). In general, significant changes in mean shoreline positions were found to be mostly associated with significant changes in mean wave direction than in wave height.

\section{Results for B2}

Comparisons between control and B2 scenario seasonal mean shoreline positions revealed evidence of significant changes only for the HIRHAM-E50 experiment and essentially only for summer $(p<<0.125$ ). Figure 10 presents these changes. Weak evidence of different shoreline 
positions' distribution was also present in autumn (not shown). In general, smaller change is predicted for this future scenario which usually produces shorelines lying between the control and the A2 scenario shorelines.

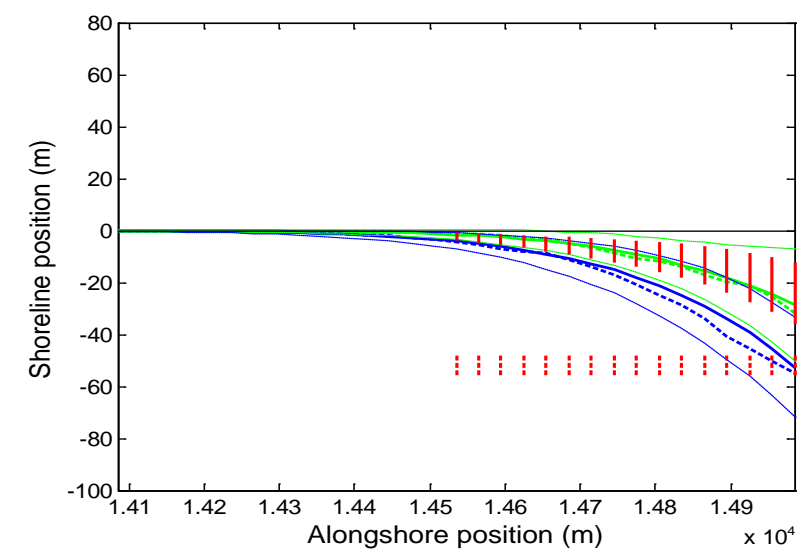

Figure 10. Results for summer for the HIRHAM-E50 B2 scenario. Formatting scheme is as shown in Figure 6.

\section{Discussion and Conclusion}

Returning to the broader issues in the Introduction, whether climate change is likely to have an impact on our shorelines and if so, will it be significant, we can draw some general conclusions. With an admittedly limited range of climate change scenarios and global weather model output it has proved to be quite difficult to find statistically significant changes in beach behaviour between the 'medium high' and 'medium low' scenarios. Indeed, the differences obtained by using the output from different models are often statistically significant. This leads us to a rather cautious position about statements regarding shoreline change resulting from climate change. While sea level changes have an obvious and direct impact on shoreline position, these effects are not included in our study which has focused on the changes induced by the atmospheric winds and pressure fields. The multiplicity of atmospheric and linked atmosphere-ocean climate models leads to a spread in forecasts. This creates (or at least unmasks) the uncertainty inherent in the atmospheric modeling. This uncertainty is then propagated into the wave hindcasting and shoreline prediction models. Despite the uncertainties we have found a measure of change due to atmospheric climate changes associated with IPCC scenarios that is robust and significant in a statistical sense:

- $\quad$ These are in late summer in med-hi scenario and in late winter in the med-lo scenario;

- $\quad$ Statistically significant changes are associated with changes in wave direction rather than wave height;

- Summer is the only season for which all experiments agree there will be statistically significant shoreline changes.

\section{ACKNOWLEDGMENTS}

The authors acknowledge the support of the Southwest Regional Development Agency, UK.

\section{REFERENCES}

Abernethy, C.L. and G. Gilbert. 1975. Refraction of wave spectra. Hydraulics Research Station, Wallingford Report INT117, May 1975.

Beniston, M., Stephenson, D. B., Christensen, O. B., Ferro, C. A. T., Frei, C., Goyette, S., Halsnaes, K., Holt, T., Jylha, K., Koffi, B., Palutikof, J., Scholl, R., Semmler, T., and Woth, K., 2007. Future extreme events in European climate: an exploration of regional climate model projections. Climatic Change, 81 (Supplement 1), 71-95.

Bradbury, A.P., Mason, T.E., and Holt, M.W., 2004. Comparison of the Performance of the Met Office UK-Waters Wave Model with a Network of Shallow Water Moored Buoy Data. Proceedings of the 8th International Workshop on Wave Hindcasting and Forecasting, Hawaii. 
CERC, 1977. Shore protection manual. Coastal Engineering Research Center, U.S. Corps of Engineers, Vicksburg.

Christensen, J. H. and Christensen, O. B., 2007. A summary of the PRUDENCE model projections in European climate by the end of this century. Climatic Change, 81(Supplement 1): 7-30.

Christensen, J.H., Christensen, O.B., Lopez, P., van Meijgaard, E., and Botzet, M., $1996 . \quad$ The HIRHAM4 Regional Atmospheric Climate Model. DMI Scientific Report No. 96-4, DMI, Copenhagen.

Christensen, J.H., T.R. Carter, M. Rummukainen and G. Amanatidis. 2007. Evaluating the performance and utility of regional climate models: the PRUDENCE project, Climatic Change, 81 (S 1), p1-6.

Cowell, P.J., Stive, M.J.F., Niedoroda, A.W., Swift, D.J.P., De Vriend, H.J., Buijsman, M.C., Nicholls, R.J., Roy, P.S., Kaminsky, G.M., Cleveringa, J., Reed, C.W., and De Boer, P.L., 2003. The coastal tract (Part 2): an applications of aggregated modelling to lower-order coastal change. Journal of Coastal Research, 19(4): 828-848.

Donelan, M., 1980. Similarity theory applied to the forecasting of wave heights, periods and directions. Canadian Coastal Conference, Burlington, Canada, pp. 47-61.

Freund, J.E., 1992. Mathematical Statistics. Prentice Hall, Inc, New Jersey, 576 pp.

Hosking, A. and McInnes, R., 2002. Preparing for the impacts of climate change on the Central South Coast of England: a framework for future risk. Journal of Coastal Research, 36(SI): 381-389.

Hulme, M., Jenkins, G.J., Lu,X., Turnpenny, J.R., Mitchell, T.D., Jones, R.G., Lowe, J., Murphy, J.M., Hasell, D., Boorman, P., McDonald, R., and Hill, S., 2002. Climate change scenarios for the United Kingdom: the UKCIP02 scientific report. Tyndall Centre for Climate Change Research, School of Environmental Sciences, University of East Anglia, Norwich, UK, 120 pp.

IPCC SRES, 2000. Special report on emissions scenarios (SRES). A special report of working Group III of the Intergovernmental Panel on Climate Change. Cambridge University Press, Cambridge, UK, 559 pp.

IPCC WG1, 2007. Climate change 2007: the physical science basis. Contribution of the Working Group I to the Fourth Assessment Report of the Intergovernmental Panel on Climate Change, Cambridge University Press, Cambridge, UK, 940 pp.

Kaas, E., Andersen, U., Flather, R.A., Willimas, J.A., Blackman, D.L., Lionello, P., Dalan, F., Elvini, E., Nizzero, A., Malguzzi, P., Pfizenmayer, A., von Storch, H., Dillingh, D., Phillipart, M., de Ronde, J., Reistad, M., Midtbø, K.H.,Vignes, O., Haakenstad, H., Hackett, B., Fossum, I., Sidselrud, L., 2001. Synthesis of the STOWASUS-2100 project: regional storm, wave and surge scenarios for the 2100 century. Danish Climate Centre Report 01-3, 27 pp.

Komar,P.D., 1998. Beach processes and sedimentation. Prentice Hall, Inc, New Jersey, 544 pp.

Pope, V.D., Gallani, M.L., Rowntree, P.R., and Stratton, R.A., 2000. The impact of new physical parameterizations in the Hadley Centre climate model: HadAM3. Climate Dynamics, 16: 123-146.

Räisänen, J., Hansson, U., Ullerstig, A., Döscher, R., Graham, L. P., Jones, C., Meier, M., Samuelsson, P., and Willén, U., 2003. GCM driven simulations of recent and future climate with the Rossby Centre coupled atmosphere - Baltic Sea regional climate model RCAO. RMK No.101, Rossby Centre, SMHI.

Roeckner, E., Arpe, K., Bengtsson, L., Christoph, M., Claussen, M., Dümenil, L., Esch, M., Giorgetta, M., Schlese, U., and Schulzweida, U., 1996. The atmospheric general circulation model ECHAM-4: Model description and simulation of present-day climate. MPI Report 218, MaxPlanck-Insitut für Meteorologie, $90 \mathrm{pp}$.

SCOPAC, 2003. Poole harbour entrance to Hengistbury Head (Poole Bay). SCOPAC Sediment transport study, $42 \mathrm{pp}$.

Sutherland J, Gouldby B. 2003. Vulnerability of coastal defences to climate change. Water and Maritime Engineering 156(WM2): 137-145.

Wikipedia 2010. http://en.wikipedia.org/wiki/Climatic_Research_Unit_email_controversy accessed 20 July 2010.

Zacharioudaki, A. and D.E. Reeve, 2010. A note on the numerical solution of the one-line model, Environmental Modeling and Software, 25, p802-807.

Zacharioudaki, A. 2008. Mathematical modelling of shoreline evolution under climate change. $\mathrm{PhD}$ thesis, Faculty of Technology, School of Engineering, University of Plymouth, 259 pp.

Zwiers, F. W. and von Storch, H., 1995. Taking serial correlation into account in tests of the mean. Journal of Climate, 8: 336-351. 